\title{
Value Evaluation of Moutai Group Based on FCFF Model
}

\author{
Jinlong Wang ${ }^{1, \mathrm{a}}$, Shulong Cai ${ }^{1, \mathrm{~b}^{*}}$,Yan $\mathrm{Xu}^{1, \mathrm{c}}$ \\ ${ }^{1}$ Harbin Finance University, Department of Accounting, Harbin, Heilongjiang, China
}

\begin{abstract}
As the stock with the highest stock price in China, Guizhou Moutai is favored by the public investors, and also focused by the local and central governments. However, in the whole investment market, in order to deal with the problem of information asymmetry between enterprises and investors, any rational investor will try to obtain more accurate enterprise information and pay attention to the analysis and suggestions of professionals, so as to ensure the safety of their investment and obtain considerable profits. Therefore, in order to reveal the accurate situation of the enterprise value under the continuous growth of Moutai group's stock price, provide investors with relevant decision-making basis, and provide useful reference information for the government departments to regulate the liquor market. This paper evaluates the enterprise value of Guizhou Moutai Group by establishing FCFF model and using the historical data collected, and then the actual value of Moutai Group is calculated and a conclusion is drawn. The research shows that: the growth of Moutai Group's stock price is in line with the development trend of the enterprise and the industry, and the enterprise value has a reasonable support, which is not unreasonably high. At the same time, the analysis shows that the growth ability, profitability and development ability of Moutai Group are relatively strong, and the enterprise has a strong development potential in the future.
\end{abstract}

\section{Introduction}

Chinese Baijiu is one of the six largest distilled spirits in the world, and is also unique traditional liquor in China. The development of liquor making technology in China has experienced the process from turbid liquor to sake, and then to distilled liquor. Since 1952, Moutai and Wuliangye have been selected as "Chinese famous liquor" products in many national famous liquor selection activities. Its unique brewing technology and mellow taste, especially Moutai, is the originator of Chinese Daqu Moutai flavor liquor, which is honored as "national liquor". While carrying forward the Chinese tradition, its existence has also added vitality and power to China's economic development, playing an unparalleled role in the long river of historical development. From the perspective of 2019, Guizhou Moutai Co., Ltd. is the largest taxpayer in Guizhou Province with a total tax amount of 32.572 billion yuan. In the stock market, the stock price of Moutai is also rising steadily. As of February 10, 2021, the stock price of Guizhou Moutai has reached a new high, breaking through 2500 yuan in succession and standing at 2600 yuan. So far, many scholars have analyzed the enterprise value of Guizhou Moutai and studied the differences of different evaluation methods.

\footnotetext{
* Corresponding author: Shulong Cai 1,b ,cslandcs1@126.com
}

\section{Literature Review}

In terms of valuation methods, Huang Win-Bin (2020) believes that some traditional valuation methods need historical financial indicators and some market multipliers, while ignoring non-financial information [1]. Horák J. (2021) believes that in the process of enterprise value evaluation, appraisers need to understand not only the evaluated enterprise, but also the external decisive influence [2]. Ji bin (2012) believes that the premise used in the establishment of the evaluation model is difficult to fully meet, but according to the scientific procedure, the conclusion will be close to the actual value, and the significance of the method is greater than the reality [3]. Liu Jie (2012) believes that dividend ratio and debt ratio will affect the valuation results of DDM, FCFE and FCFF models. The lower the dividend ratio and debt ratio are, the smaller the valuation difference of the three models is, and vice versa [4]. Gao Cong (2018) believes that in the evaluation process, because there are no clear provisions on the required parameters, it is inevitable that there will be problems in this process, and the accuracy of using different models to evaluate the weighted value of the results is higher [5].In terms of the research on the enterprise value of Guizhou Moutai, Wang Ya (2017) used the FCFF model to estimate the value of Moutai Group at 1143158199343 yuan. She believes that the model is only applicable to the value evaluation of listed enterprises in the growth and mature stages [6].Li Bing (2018) used two methods to evaluate the enterprise value of Moutai Group, 
and combined these two methods to judge that the market value of Moutai may be overestimated [7].Cao Jie (2019) took December 31, 2018 as the base date of evaluation, and the difference rate between the stock price of Guizhou Moutai and the actual closing price was $2 \%$. He believed that the stock price of Moutai was not unreal high, which was in line with its internal real value [8]. Xu Huojun (2019) based on the valuation of Moutai Group at the end of 2017 as 859.474 billion yuan, and he thinks that it can be evaluated and calculated according to the possible range of some ratios to give users a value reference range [9]. Ma Nan (2020) used a three-stage model to study the intrinsic stock price of Moutai, which was 997.48 yuan. He believed that the stock price of Guizhou Moutai would be overvalued in the evaluation [10].

To sum up, domestic scholars have achieved fruitful results in the research on the analysis of the enterprise value of Moutai Group and the selection of methods to evaluate the enterprise value. But Baijiu group's analysis is only conducted as a Baijiu manufacturing enterprise, without considering the cultural consumption attributes of liquor making enterprises and liquor products; and the analysis of the Guizhou Moutai group is not enough. In the past, the knowledge of Baijiu was only a drink as a kind of emotional exchange. But now more and more people will take high-end Baijiu as a collection, not just as a drink. In view of this, this article considers the cultural consumption attributes of Baijiu liquor, and also takes into account the change of the high-end Baijiu as a collector. The latest data of the capital market are used to analyse the Guizhou Moutai group and evaluate its enterprise value. This paper not only gives the reasonable basis of investment decision-making from the perspective of investors, but also gives some reasonable countermeasures and suggestions from the perspective of government regulators.

\section{Model of Moutai enterprise value evaluation based on FCFF}

\subsection{Basic Formula}

Discount the free cash flow of the enterprise to get the whole value of the enterprise, or subtract the value of interest paying debt on this basis to get the model of the total equity value of the shareholders, that is, the discount model of the free cash flow of the enterprise. The basic formula of free cash flow discount model is as follows:

$$
\mathrm{V}=\sum_{t=1}^{n} \frac{F C F F_{t}}{(1+W A C C)^{t}}
$$

Among them:

$\mathrm{V}$ _-Enterprise overall value

$\mathrm{FCFF}_{\mathrm{t}}$ - free cash flow of enterprises in the $\mathrm{t}$-th year

WACC — weighted average cost of capital

$\mathrm{WACC}=\frac{E}{E+D} \times R_{e}+\frac{D}{E+D} \times R_{d} \times(1-T)$

Among them:

$\mathrm{R}_{\mathrm{e}}$ Cost of capital stock is the necessary rate of return for investors

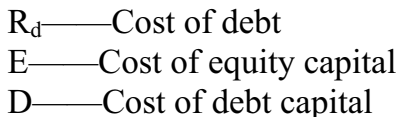

\subsection{Stable growth Model}

If the free cash flow of an enterprise continues to grow at a constant growth rate and the income is indefinite, then the stable growth free cash flow of an enterprise can be used to evaluate the overall value of the enterprise. The formula is as follows:

$$
\mathrm{V}=\frac{F C F F_{1}}{C}
$$

Among them:

$\mathrm{FCFF}_{1} \_$Free cash flow of the first period after the base date

$\mathrm{C}-$ Capitalization rate

$\mathrm{C}=$ WACC $-\mathrm{g}, \mathrm{g}$ is a fixed growth rate

\subsection{Two stage Model}

If the free cash flow of the evaluated enterprise is expected to fluctuate rapidly in a certain period of time, and then enter the stable development stage, and the income period of the stable development stage is infinite, it is suitable for the two-stage model. The calculation formula is as follows:

$$
\mathrm{V}=\sum_{t=1}^{n} \frac{F C F F_{t}}{(1+W A C C)}+\frac{F C F F_{n+1}}{(W A C C-g) \times(1+W A C C)^{n}}
$$

Among them:

$\mathrm{FCFF}_{\mathrm{n}+1}$ refer to the free cash flow of the enterprise in the next year of the forecast period. If the sustainable growth rate $G>0$, then $F_{C F F}$ should consider the increase of working capital and the part of capital expenditure greater than depreciation and amortization. In other words, in order to maintain the expected growth rate, it is necessary to deduct the corresponding capital expenditure and net increase of working capital from the free cash flow of the enterprise.

In the second stage of the two-stage model, $\frac{F C F F_{n+1}}{W A C C-g}$ is also called sustainable value.

\subsection{Three stage Model}

The three-stage model includes the initial high growth stage, the transformation stage of declining growth rate and the stable growth stage. The overall value of the enterprise is the sum of the present value of the free cash flow of the enterprise in the three stages. When the income period of the steady growth stage is infinite, the calculation formula of the three-stage model is as follows:

$$
\mathrm{V}=\sum_{t=1}^{n} \begin{gathered}
\frac{F C F F_{0} \times(1+g)^{t}}{(1+W A C C)^{t}}+\sum_{i=n_{1}+1}^{n} \frac{F C F F_{t}}{(1+W A C C)^{t}} \\
+\frac{F C F F_{n} \times\left(1+g_{n}\right)}{\left(W A C C-g_{n}\right) \times(1+W A C C)^{n}}
\end{gathered}
$$

In the above models, it is assumed that the free cash flow in the future income period will be realized at the end of each year. 
The FCFF valuation model of Moutai Group is established:

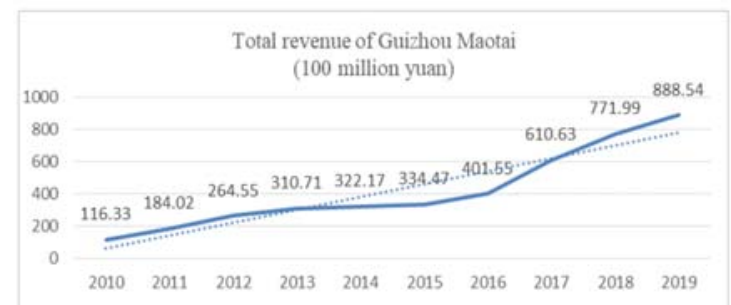

Figure 1. Total operating revenue of Guizhou Moutai from 2010 to 2019

Through the comparative analysis of the total business income of Guizhou Moutai Group in recent years, we can see that the growth rate of the total business income of Moutai Group accelerated in 2016, and its growth rate also maintained at a relatively high value in 2017 , and the future development prospects are all the way good. Using the industry cycle theory to predict, after a round of rapid growth, Guizhou Moutai Group will enter a stage of stable development, so the two-stage model will be used to evaluate it.

The assumptions are as follows:

Table1. Two stage model prediction table

\begin{tabular}{|c|c|c|}
\hline Particular year & Stage & Characteristic \\
\hline $2019-2021$ & The first stage & Rapid growth \\
\hline After 2021 & The second stage & Stable development \\
\hline
\end{tabular}

\section{Valuation of Moutai enterprise value evaluation based on FCFF}

\subsection{The Prediction of Free Cash Flow of Enterprises}

\subsubsection{The first stage is to estimate the relevant parameters of enterprises in 2020 and 2021}

First, estimate the net profit of the enterprise from 2020 to 2021. Get the net profit of the enterprise from the stock bar from 2016 to 2019, and then calculate the month on month growth rate of the net profit of each year. Then, the weighted average growth rates of 2017, 2018 and 2019 are calculated with weights of $0.2,0.3$ and 0.5 respectively, and the data of $29.60 \%$ is obtained as the growth rate of net profit in 2020. Similarly, the net profit growth rate in 2021 is $25.75 \%$. Then, it can be calculated that the net profit in 2020 and 2021 will be 56.985 billion yuan and 71.659 billion yuan respectively.

Table2. Two stage model prediction table

\begin{tabular}{|c|c|c|c|c|}
\hline (100million yuan) & 2016 & 2017 & 2018 & 2019 \\
\hline Net profit & 179.3 & 290.1 & 378.3 & 439.7 \\
\hline $\begin{array}{c}\text { Month on month } \\
\text { growth rate of net } \\
\text { profit }\end{array}$ & - & $61.80 \%$ & $30.40 \%$ & $16.23 \%$ \\
\hline
\end{tabular}

Secondly, we estimate the interest expense in 2020 and 2021. From the data obtained, we can calculate the percentage of the annual interest expense in the net profit of the year, and give the weight of $0.1,0.1,0.4$ and 0.4 to 2016, 2017, 2018 and 2019 respectively. The percentage of the interest expense in the net profit of the year in 2020 is $0.39 \%$, and the predicted value of the interest expense in 2020 is 222 million yuan. Similarly, the percentage of interest expense in net profit in 2021 is $0.37 \%$, and the predicted value of interest expense in 2021 is 265 million yuan.

Table3. Statistics of interest expense in 2016-2019

\begin{tabular}{|c|c|c|c|c|}
\hline (100 million yuan) & 2016 & 2017 & 2018 & 2019 \\
\hline Interest expense & 1.230 & 1.352 & 1.363 & 1.458 \\
\hline $\begin{array}{c}\text { Percentage of net } \\
\text { profit }\end{array}$ & $0.69 \%$ & $0.47 \%$ & $0.36 \%$ & $0.33 \%$ \\
\hline
\end{tabular}

Thirdly, the depreciation and amortization in 2020 and 2021 are estimated. From the data obtained, we can calculate the percentage of annual depreciation and amortization in the annual net profit of the enterprise. According to the weight of $0.1,0.1,0.4$ and 0.4 in 2016, 2017, 2018 and 2019, the percentage of depreciation and amortization in the net profit of 2020 is $3.25 \%$, and the predicted value of depreciation and amortization in 2020 is 1.852 billion yuan. Similarly, the depreciation and amortization in 2021 accounted for $3.11 \%$ of the net profit of the year, and the depreciation and amortization in 2021 was 2.229 billion yuan.

Table4. Statistics of depreciation and amortization in 2016-

\begin{tabular}{|c|c|c|c|c|}
\hline \multicolumn{5}{|c}{2019} \\
\hline $\begin{array}{c}\text { (100 million yuan) } \\
\text { ampreciation and } \\
\text { amortization }\end{array}$ & 2016 & 2017 & 2018 & 2019 \\
\hline $\begin{array}{c}\text { Percentage of net } \\
\text { profit }\end{array}$ & $5.15 \%$ & 11.16 & 11.65 & 12.33 \\
\hline
\end{tabular}

Then, we estimate the capital expenditure in 2020 and 2021. Capital expenditure is the increase of fixed assets, intangible assets and other long-term assets. Therefore, it can be found in the cash paid for the purchase and construction of fixed assets, intangible assets and other long-term assets in the cash flow statement. From the data obtained, the percentage of annual capital expenditure in net profit is calculated, and the average percentage of capital expenditure in net profit from 2016 to 2019 is $5.24 \%$, which is used as the percentage of capital expenditure in profit in 2020 and 2021. The predicted value of capital expenditure in 2020 and 2021 is 2.986 billion yuan and 3.755 billion yuan respectively.

Table5. Statistics of capital expenditure in 2016-2019

\begin{tabular}{|c|c|c|c|c|}
\hline (100 million yuan) & 2016 & 2017 & 2018 & 2019 \\
\hline Capital expenditure & 10.19 & 11.25 & 16.07 & 31.49 \\
\hline $\begin{array}{c}\text { Percentage of net } \\
\text { profit }\end{array}$ & $5.68 \%$ & $3.88 \%$ & $4.25 \%$ & $7.16 \%$ \\
\hline
\end{tabular}

Finally, we estimate the net increase of working capital in 2020 and 2021. The increase in operating assets is equal to current assets minus current liabilities, so the required data can be obtained from the balance sheet. The percentage of working capital increase in net profit in 2017,2018 and 2019 is weighted by $0.2,0.4$ and 0.4 respectively, and the weighted average is $57.62 \%$, which is used as the parameter to estimate the working capital increase in 2020 and 2021. It can be concluded that the increase of working capital in 2020 and 2021 will be 32.835 billion yuan and 41.290 billion yuan respectively.

Table6. Statistics of working capital in 2016-2019

\begin{tabular}{|c|c|c|c|c|}
\hline (100 million yuan) & 2016 & 2017 & 2018 & 2019 \\
\hline Working capital & 531.6 & 736.3 & 954.6 & 1179.1 \\
\hline
\end{tabular}




\begin{tabular}{|c|c|c|c|c|}
\hline $\begin{array}{c}\text { Increase in working } \\
\text { capital }\end{array}$ & - & 204.7 & 218.3 & 224.5 \\
\hline $\begin{array}{c}\text { Percentage of net } \\
\text { profit }\end{array}$ & - & $70.56 \%$ & $57.71 \%$ & $51.06 \%$ \\
\hline
\end{tabular}

Through the above analysis and calculation, we can get the following table:

Table7. Prediction table of required parameters for 20202021

\begin{tabular}{|c|c|c|}
\hline & 2020 & 2021 \\
\hline Net profit & 569.85 & 716.59 \\
\hline Interest expenses & 2.22 & 2.65 \\
\hline Depreciation and amortization & 18.52 & 22.29 \\
\hline Capital expenditure & 29.86 & 37.55 \\
\hline Increase in working capital & 328.35 & 412.90 \\
\hline It can be calculated that: \\
$F C F F_{2020}=[569.85+2.22 \times(1-25 \%)$ & $+18.52]-$ \\
$(29.86+328.35)=231.83(100$ million yuan $)$ \\
$F C F F_{2021}=[716.59+2.65 \times(1-25 \%)$ \\
$(37.55+412.90)=290.42(100$ million yuan $)$
\end{tabular}

According to the annual report data, the income tax rate is $25 \%$.

\subsubsection{The relevant parameter values of the second stage after 2021 are estimated}

First, we estimate the stable growth rate of enterprises. For the valuation of $\mathrm{G}$, we use the most easily available and reliable weighted average of GDP in recent five years to calculate. The GDP growth rates in the five years are $6.8 \%, 6.9 \%, 6.7 \%, 6 \%$ and $2.3 \%$ respectively. Most of the reasons for the drastic changes in the data in 2020 are due to the impact of the epidemic situation. As the epidemic situation in 2021 is expected to have some impact on the economy, the data in 2020 is still of reference value. Finally, the average GDP growth rate of $5.74 \%$ in recent five years is taken as the final value of $\mathrm{G}$.

Finally, get the $F C F F_{2022-a f t e r w a r d s}=290.42 \times$ $(1+5.74 \%)=307.09(100$ million yuan $)$

\subsection{Forecast of Discount rate of Future Income}

Under the FCFF model, the discount rate of future earnings adopts the value of weighted average cost of capital (WACC). We can see from the above $\mathrm{WACC}=\frac{E}{E+D} \times R e+\frac{D}{E+D} \times R d \times(1-T), \quad$ Next, we estimate the required parameters in turn.

First, estimate the market value (E) of the company's equity and the cost of the company's liability capital (d). The relevant data of the last five years can be obtained from the stock bar, as shown in the table below. Therefore, we can get the average value of the share capital and debt capital in the past five years, respectively, $73.25 \%$ and $26.75 \%$, as the required parameter value.

\begin{tabular}{|c|c|c|c|c|c|} 
Table8. & \multicolumn{5}{c|}{ Proportion of equity and debt capital } \\
\hline & 2015 & 2016 & 2017 & 2018 & 2019 \\
\hline $\begin{array}{c}\text { Market value of } \\
\text { equity (E) }\end{array}$ & 662.3 & 759.0 & 960.2 & 1174 & 1419 \\
\hline $\begin{array}{c}\text { Cost of debt } \\
\text { capital (D) }\end{array}$ & 200.7 & 370.4 & 385.9 & 424.4 & 411.7 \\
\hline Total & 863.0 & 1129.4 & 1346.1 & 1598.4 & 1830.7 \\
\hline $\begin{array}{c}\text { Proportion of } \\
\text { equity capital }\end{array}$ & $76.74 \%$ & $67.20 \%$ & $71.33 \%$ & $73.45 \%$ & $77.51 \%$ \\
\hline
\end{tabular}

\begin{tabular}{|c|c|c|c|c|c|}
\hline $\begin{array}{c}\text { Debt capital } \\
\text { ratio }\end{array}$ & $23.26 \%$ & $32.80 \%$ & $28.67 \%$ & $26.55 \%$ & $22.49 \%$ \\
\hline
\end{tabular}

Secondly, the cost of equity (RE) will be estimated by using the capital asset pricing model. The capital asset pricing model assumes that all investors invest according to Markowitz's asset selection theory, and the estimates of expected return, variance and covariance are exactly the same. Investors can borrow freely. The formula is as follows:

Among them:

$$
\mathrm{R}=\mathrm{R}_{\mathrm{f}}+\beta \quad\left(\mathrm{R}_{\mathrm{m}}-\mathrm{R}_{\mathrm{f}}\right)
$$

$\beta-$ Risk index is used to measure the volatility of individual stocks or stock funds relative to the whole stock market

$\mathrm{R}_{\mathrm{f}}$ - Risk free rate of return

$\mathrm{R}_{\mathrm{m}}$-Average return of market portfolio

$\left(\mathrm{R}_{\mathrm{m}}-\mathrm{R}_{\mathrm{f}}\right) \longrightarrow$ Market risk premium rate

For $R_{f}$, we choose $4.12 \%$ of the average yield of $4.27 \%$ and $3.97 \%$ of the five-year treasury bonds in recent two years as its value. For RM, we choose the average $21.57 \%$ of the closing index of Shanghai stock index at the end of each year from 1990 to 2020 as its value. Then (RM RF) equals $17.45 \%$.

About $\beta$ we use the method of regression analysis to forecast the monthly return of Shanghai stock index and Guizhou Moutai. As shown in the figure below, so $\beta=$ 2838 。

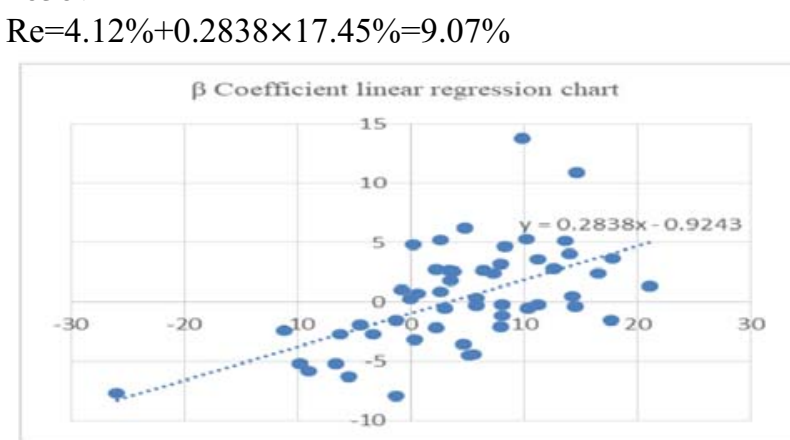

Figure 2. $\beta$ Coefficient linear regression chart

Thirdly, estimate the cost of debt (RD). It uses the interest rate set by its borrowing bank as the valuation of the cost of debt. However, Moutai Group has not borrowed from banks for a long time, so we use the average value of $4.67 \%$ of the commercial loan interest rate stipulated by the Bank of China, which is $4.35 \%$ within one year, $4.75 \%$ within one to five years and $4.90 \%$ over five years, as the estimation value of this parameter.

Finally, we can calculate WACC $=73.25 \% \times$ $9.07 \%+26.75 \% \times 4.67 \% \times(1-25 \%)=7.58 \%$

\subsection{Estimate the Enterprise Value of Moutai}

Bring the calculated parameters into the formula:

$$
\begin{aligned}
& \mathrm{V}=\sum_{t=1}^{n} \frac{F C F F_{t}}{(1+W A C C)}+\frac{F C F F_{n+1}}{(W A C C-g) \times(1+W A C C)^{n}} \\
& =\frac{231.83+290.42}{(1+7.58 \%)}+\frac{307.09}{(7.58 \%-5.74 \%) \times(1+7.58 \%)^{2}}
\end{aligned}
$$$$
=485.45+14442.12
$$

$=14927.57$ (100 million yuan) 
To sum up, the enterprise value of Guizhou Moutai Group on December 31, 2019 is 1492.757 billion yuan. According to the company's annual statements, the company has a total of 1.256 billion shares, so the share price of Guizhou Moutai Group is 1492.757 billion yuan $\div 56=1188.50$ yuan.

\section{Conclusions}

According to the collected data, the stock price of Guizhou Moutai on December 31, 2019 is 1165.98 yuan, and the value of this appraisal is 1188.50 yuan, with a difference of 22.52 yuan and a difference rate of $1.93 \%$, which is within the acceptable range.

Based on the above analysis of Guizhou Moutai group, it can be seen that as the leading brand of the Chinese Baijiu industry, its growth ability, profitability and development ability are strong according to the predicted net profit of 56 billion 985 million yuan and 71 billion 659 million yuan in 2020 and 2021 and the increase of working capital in 2020 and 2021. 32 billion 835 million yuan and 41 billion 290 million yuan respectively. Besides, because of its strong cultural adhesion, Baijiu industry carries cultural consumption factors such as social etiquette and emotional communication in the traditional Chinese histories, which surpass the functional attributes of the product itself. The strength of brand influences the quality of Baijiu enterprise. The cultural and historical attributes of the brand need time to accumulate, and there is no time to be the foundation and no accumulation of history. The emerging Baijiu brand is hard to be recognized and accepted by people. Therefore, the liquor companies with the foundation of the old famous liquor will have new opportunities and have greater advantages in the future development. If Baijiu enterprises want to better promote the market, it is more important to create their unique brand image, and the shaping of brand image should include culture, tradition, craft, and history and so on. And in recent years, with the development of economy and the improvement of people's living standards, people not only regard Moutai and other high-grade liquor as drinks, but also explore their collection value. Therefore, in the future, the development prospect of high-grade wine is considerable, and the development potential is huge. At the same time, it also requires the relevant departments such as the state and government to supervise and control the high-end Baijiu enterprises, supervise their production methods and processes, and supervise the market order in the transaction. Then we should know the production cost of Baijiu production and understand the rationality of Baijiu liquor pricing, avoid some illegal elements "stir up wine" for the sake of profiteering, and drive up the price of wine to create unnecessary chaos in the economic market.

\section{Acknowledgment}

Project source : (1)2018 Heilongjiang Provincial Universities Basic Scientific Research Business Expenses Scientific Research Project, No. 2018-KYYWF-E018; (2)2020 Heilongjiang Provincial Universities Basic
Scientific Research Business Expenses Scientific Research Project, No. 2020-KYYWF-010

\section{References}

1. Huang Win-Bin;Liu Junting;Bai Haodong;Zhang Pengyi.Value assessment of companies by using an enterprise value assessment system based on their public transfer specification[J].Information Processing \& Management,2020(prepublish).

2. Horák J.;Rowland Z.; ̌́ule ř $\quad$ P.;Vrbka Jaromír;Vitková Pavla.The applicability of FCFF method evaluating an enterprise of Real Estate segment[J].SHS Web of Conferences,2021,91:01042-01042.

3. Liu Jie. Comparative analysis of three discounted cash flow models [J]. Finance and accounting monthly. 2012 (28); 72-73

4. Ji bin. Valuation of listed companies based on discounted free cash flow model: a case study of Guizhou Moutai [J]. Financial and accounting communication. 2012 (27): 83-85

5. Gao Cong. Case Study on enterprise value evaluation of Guizhou Moutai [D]. Shenzhen: Shenzhen University, 2018 (07)

6. Wang Ya. Enterprise value evaluation (free cash flow model) - a case study of Guizhou Moutai [J]. Science and technology economic market. 2017 (05)

7. Li Bing. Research on valuation of Guizhou Moutai [D]. Hubei: Huazhong University of science and technology, 2018 (05)

8. Cao Jie. The application of FCFF model in Guizhou Maotai enterprise value evaluation [J]. Hebei enterprise. 2019 (11)

9. $\mathrm{Xu}$ Hui Jun. Value evaluation of Baijiu Industry Listed Companies in China [J]. Journal.2019 (02)

10. Ma Nan. Guizhou Maotai valuation [D]. Yunnan: Yunnan University of Finance and economics, 2020: (07)

11. Ji Luxue. Research on the value evaluation of Qingdao beer enterprises based on FCFF model [D]. Jiangsu: China University of mining and technology, 2020

12. Cao Pingping. Discussion on asset appraisal method and its selection $[\mathrm{J}]$. China management informatization. 2020 (13): 25-27 